\title{
ENHANCED ACADEMICIANS ENGAGEMENT: EVIDENCE FROM GAMIFICATION INTERVENTIONS IN HIGHER EDUCATION INSTITUTES
}

\author{
KDV Prasad ${ }^{* 1}$ (iD, Mruthyanjaya Rao ${ }^{2}$ \\ ${ }^{* 1}$ Adjunct Faculty, IIHRD, Financial District, Gachibowli, Hyderabad 500032, Telangana, India \\ 2 Senior Manager, Karvy Stock Broking Limited, Financial District, Gachibowli, Hyderabad 500032, \\ Telangana, India
}

DOI: https://doi.org/10.29121/ijetmr.v7.i9.2020.779

\section{Article Citation: KDV Prasad, and Mruthyanjaya Rao. (2020). \\ ENHANCED ACADEMICIANS ENGAGEMENT: EVIDENCE FROM GAMIFICATION INTERVENTIONS IN HIGHER EDUCATION INSTITUTES. International Journal of Engineering Technologies and Management Research, 7(9), 24-30. https://doi.org/10.29121/ijetmr.v7 i9.2020.779}

Published Date: 16 September 2020

Keywords:

Gamification

Resource Pooling

Employee Engagement

Motivation

Academician

\section{ABSTRACT}

Background: This paper presents an outcome of gamification interventions in higher educational institutes to enhance the engagement of the teaching staff, the academicians. The academicians' engagement is an important component to enhance learning and timely course completion and for excellent student outcomes. In the recent past the gamification being used as a beneficial strategy in several areas such as business, education, e-learning, research and development and behavioral change of employees.

Method: The authors have applied gamification interventions on Academicians of Engineering colleges around Hyderabad to see the effect of gamification on academician's motivation, engagement, loyalty, dedication to the organization, and turnover. A group of 150 academicians, the teaching staff were tested using before gamification and postgamification survey instruments, a questionnaire.

Results: The reliability of the survey instrument assessed measuring Cronbach-alpha statistics, descriptive statistics, and General Linear Model analysis was carried out to predict the influence of gender and academician's gamification choices on study variables. The postgamification results reveal a statistically significant influence on motivation, engagement, whereas gamification intervention is a not good predictor of employee turnover and loyalty. The results from the General Linear Model analysis indicate the use of games in non-game context immensely motivates the employees and academicians inclined towards quests and challenges.

Conclusions: The gamification is new and the study is novel can be successfully applied to engagement the academicians, motivating intrinsically if used correctly.

\section{INTRODUCTION}

The continuous technological development and in new-normal situations, the traditional methods of teaching staff engagement with extrinsic motivation with enhanced pay yield only short-term benefits, and leads to turnover and disengagement. In the gamification environment, where game mechanics are applied to non-game contexts to

(c) 2020 The Author(s). This is an open access article distributed under the terms of the Creative Commons Attribution License, which permits unrestricted use, distribution, and reproduction in any medium, provided the original author and source are credited. 
motivate the employees to carry out extraordinary things. The employees expect a fun, competition, and challenges in the working environment, and the gaming techniques are becoming essential elements of the organization to motivate, attract, and retain talent (Meister, 2015). Academician's engagement is top of the mind of any higher education institute (HEI) and the gamification interventions can assist to relieve the miseries of untold stories of teaching professionals. Over the two decades, the gamification was used in several ways from crowdsourcing in China where the consumers were provided an opportunity to design the vehicles with the results being displayed on leaderboards (McCormick, 2013) to Linked employee bio-data/curriculum vitae filled in a form which tracks the percentage of information was filed by the applicant or visitor using a track bar. Millet (2017) has successfully experimented with gamification mechanics for training and development.

The badges, levels, leader boards, behavioral change of an academician is the heart of the gamification. The gamification intervention, if applied can create the teaching more interesting, and enhanced academician engagement (Prasad et al. 2020).

\section{REVIEW OF LITERATURE}

Prasad et al. (2019) reported the benefits of gamification intervention improving operational efficiency and enhanced employee engagement in the workplace and suggested gamification can be applied in education to improve the academicians' performance. Gamification is a novel and new-age strategy embedded with game elements, and game-mechanics, and artifacts, in a non-gaming environment to enhance the engagement of people, motivate employees, promote learning to provide solutions to the problems of any kind (Kapp 2013). The gamification principles were used in education, teaching, and healthcare systems. The gamification, if applied correctly. play a crucial role in an organization's business strategies and will be the dominant motivating factor (Donato and Link 2013). Gamification can be successful and productive even where the areas the performance declined drastically and definite need enhancement such as business organizations, health care systems, and educational institutions (Fitz-Walter et al. 2011).

The holistic addiction of game mechanics in teaching and training improves the academicians' engagement student output. A reward-based mechanism is needed in gamification interventions to enhance the academician's engagement and motivation. Gamification can influence academician's behavior and can act as a catalyst by enhancing motivation through game design elements (Blohm and Leimeister, 2013). The gamification needs to be considered a beneficial strategy to enhance academician's engagement and student success. Tarek Buhagiar and Christopher Leo (2018) suggested that academician's experiences toward gamification are positive, the performance of students is statistically significant. Murugappan et. al. (2018) emphasized the need for gamified i-campus in educational institutes and gamification-based learning to be an integral using the Internet of Thing (IoT) enabled the smart campus for academicians motivation and employee engagement.

\section{RESEARCH GAP}

To see if gamification techniques, like leader boards, rewards, team-building exercises, motivation will enhance academicians motivation, engagement in higher education institutes

\section{THEORETICAL FRAMEWORK}

The theoretical framework followed using the models of Prasad et al. (2020)) is presented in Figure 1.

Before implementing the gamification to enhance academician's performance, enhanced engagement, and efficiency specific objectives need to be considered.

In the recent past, the higher educations institutions considering the gamified approach in teaching students However, to be successful the approach should be holistic, is not possible to achieve and create a level-headed teaching environment. A proactive framework with a positive teaching approach as to how to apply the framework in creating engaging, challenging, appealing, attracting, and appealing experiences in academicians workplace,. The teaching algorithm works on many gaming dynamics such as behaviors, classroom cleanliness, the ambiance of the infrastructure, communication, frequency of the students, institution timings, and more. Deploying these gaming dynamics yield better results leading to a great academician achievement for the reason of complete involvement in 
the system. A thematically represented framework of the new-age gamification for the organizations for enhancing their employee engagement and efficiency presented in (Figure 1), and this can be easily applied in the higher educational institutions. The full description of the framework is out of the scope of this study.

\subsection{OBJECTIVES}

- To understand the level of gamification on the motivation of academicians.

- To examine can gamification is useful in academicians turnaround, loyalty, and commitment

- To statistically examine the influence of gamification in academicians engagement in the higher education institute

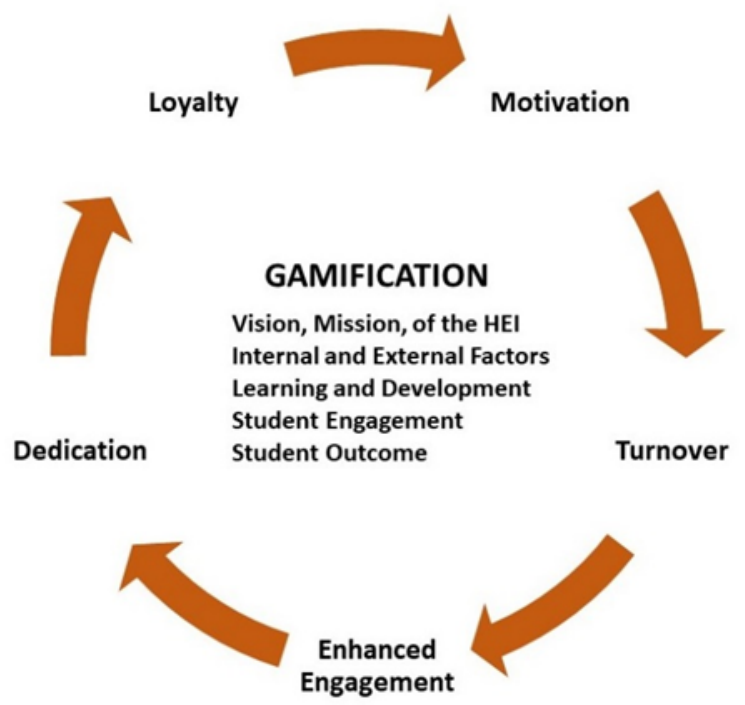

Figure 1: Gamification Model for enhancing the Academician Engagement

\section{RESULTS AND DISCUSSIONS}

\subsection{METHODOLOGY}

The pre and post-gamification experimental data on gamification variables academicians engagement, motivation, turnover, dedication, loyalty were collected using a survey instrument, a pre- and post-gamification questionnaire. The study has multiple dependent variables academician motivation, engagement, turnover, dedication, and academician's loyalty. The gamified environment consists of points, leaderboards, badges, appreciation based on the completion of tasks during that period. The scales used for this was motivation scale (Cerasoli et al. 2014), Engagement scale (Schaufeli et al., 2007), Loyalty scale (Matzler and Renzl, 2006), Dedication was measured based on (Mowday et al,. 1979) and turnover by using the scale of Bhatnagar 2007.

\subsection{HYPOTHESES}

$H_{a 1}$ : A gamified environment enhances motivation, engagement, commitment, loyalty, and maintain better academicians turnover

\subsection{DATA ANALYSIS}

The respondents' responses were keyed into Excel document and the analysis was carried out using Statistical Package for Social Sciences ver 26 for testing of hypothesis. 
The reliability of the instrument was assessed measuring the Cronbach alpha (1951) vale and overall value for all the study variables are $>0.7$, and the statements which measured $<0.4$ Cronbach alpha were not considered for analysis.

\subsection{DESCRIPTIVE STATISTICS}

The means values of $>5$ on a scale of 10 indicating the constructs are contributing well for research (Table 1). The standard deviations indicate the variations in the responses of the respondents in pre- and post-gamification experiments.

Table 1: Descriptive Statistics for all constructs

\begin{tabular}{|c|c|c|c|c|}
\hline & \multicolumn{2}{|c|}{ Pre-Gamification } & \multicolumn{2}{c|}{ Post-Gamification } \\
\hline & Mean & Standard deviation & Mean & Standard deviation \\
\hline Motivation & 7.74 & 1.64 & 7.15 & 1.03 \\
\hline Engagement & 7.63 & 1.36 & 7.13 & 1.24 \\
\hline Turnover & 7.85 & 1.32 & 6.70 & 1.47 \\
\hline Dedication & 6.71 & 1.4 & 6.20 & 1.62 \\
\hline Loyalty & 5.84 & 1.67 & 6.35 & 1.80 \\
\hline Source: Primary data & \multicolumn{4}{|l}{} \\
\hline
\end{tabular}

All the assumptions for Multiple Anova Analysis of Variance and normality of data used using Shapiro Wilk's test, the correlation in the. correlation matrix (not presented) were $>0.6$ indicating that there is no multicollinearity. The Box M value of 17.675 with $p>0.05(0.345)$ for pre-gamified and Box'sM 19.345, p>0.05(0.296) indicate no statistically significant difference for equality of covariance in both the environments. There were no outliers in the data as indicated by Mahalanobies distances 18.77 which is less than the upper limit of 21.57.

\subsection{GENERAL LINEAR MODEL ANALYSIS}

The results indicate statistically siginficant in both pre- and post-gamfication indicating the influence of gamification in academicians (Table 2).

Table 2: Multivariate Statistics (results of General Linear Model Analysis)

\begin{tabular}{|c|c|c|c|c|}
\hline Environment & Effect & Value & $\mathrm{F}$ & Sig. \\
\hline Pre-gamification & Pillai's Trace & .163 & 3.330 & .007 \\
\cline { 2 - 5 } & Wilks' Lambda & .671 & 3.330 & .007 \\
\cline { 2 - 5 } & Hotelling's Trace & .234 & 3.330 & .006 \\
\cline { 2 - 5 } & Roy's Largest Root & .242 & 3.330 & .008 \\
\hline Post-Gamification & Pillai's Trace & .173 & 3.028 & .0122 \\
\cline { 2 - 5 } & Wilks' Lambda & .800 & 3.028 & .022 \\
\cline { 2 - 5 } & Hotelling's Trace & .215 & 3.08 & .010 \\
\cline { 2 - 5 } & Roy's Largest Root & .215 & 3.08 & .010 \\
\hline \multicolumn{4}{|l|}{ Source: Primary data } \\
\hline
\end{tabular}

\subsection{INFERENCE FROM DESCRIPTIVE STATISTICS}

Table (3) presents the mean of all study variables in pre and post gamification environments indicating motivation, engagement, increased and turnover decreased and there are no significant changes in loyalty and dedication in Academicians. 
Table 3: Descriptive statistics of study variable (pre- and post-gamification)

\begin{tabular}{|l|l|l|l|}
\hline Variable & Environment & Mean & Standard deviation \\
\hline \multirow{2}{*}{ Motivation } & Pre-gamification & 7.32 & 1.52 \\
\cline { 2 - 4 } & Post-gamification & 7.81 & 1.67 \\
\hline \multirow{2}{*}{ Engagement } & Pre-gamification & 7.37 & 1.22 \\
\cline { 2 - 4 } & Post-gamification & 7.54 & 1.37 \\
\hline \multirow{2}{*}{ Durnover } & Pre-gamification & 8.15 & 1.03 \\
\cline { 2 - 4 } & Post-gamification & 6.93 & 1.14 \\
\hline \multirow{2}{*}{ Dedication } & Pre-gamification & 6.87 & 1.57 \\
\cline { 2 - 4 } & Post-gamification & 6.83 & 1.56 \\
\hline \multirow{2}{*}{ Loyalty } & Pre-gamification & 5.91 & 1.34 \\
\cline { 2 - 4 } & Post-gamification & 5.89 & 1.35 \\
\hline \multicolumn{2}{|l|}{} \\
\hline
\end{tabular}

\section{DISCUSSION}

The dependent variable motivation is statistically significant pin post-gamification indicating the academicians intrinsically motivated when subjected gamified environment with an increase in average motivation levels and the results are in line with (Cerasoli et al. 2014). Academician's engagement also statistically significantly improved when tested under a gamified environment and similarly, turnover decreased in post-gamification. However, there were statistically significant results were observed in the study variables dedication, and loyalty, indicating the gamification is not a good predictor of these two variables. The results are compared with that of (Hammadi et al., 2017; Bhatnagar, 2007; Narayanan, 2014; and Robson et al. 2016). The gamification intervention has no significant effect on loyalty and dedication in academicians in higher education institutes (Lamn and Meeks, 2009; Robson et al. 2016). The results were presented from the respondents' data of 150 academicians considering 5 study variables as dependent variables and General Linear Model (GLM) analysis performed. Some of the activities of the gamified environment stimulated the academicians in enhancing engagement, motivation, behavioral change, and reducing the turnover. The management of higher education institutes should the teaching interest with a performance-based reward system based on students outcomes applying new methods like team building, quests out the institute (Basten, 2017). Gamification is a gamechanger in higher education institutes with a fun and playful teaching environment (Werbacha and Hunter, 2012).

\section{CONCLUSIONS}

Central Message of this research: The gamification is new and the study is novel as there is very sparse literature is available on gamification interventions in the higher education institutes.

Real-world implications to the business today: The application of the gamified approach is well received amongst the academicians and students. The identification of the areas where gamification is beneficially applied is important. A stakeholder's approval is a must before implementing the gamification.

Audience and why a busy academician should read the article: This gamification and the mechanics usually attract any academician as it is novel, challenging, not monotonous. This is a new approach and academicians will receive well this approach in pursuit of professional perfection.

Research conducted to support the argument and logic: The research instrument, survey questionnaire was used and the responses collected from the academicians both pre- and post-gamified environment and the analysis was done and results indicated the gamification approach can be used in higher education institutes.

Academic, professional, personal expertise to make the argument convincing: As explained above, this approach is highly recommendable to reduce the stress levels amongst the working academicians, in particular higher education institutes. The authors draw the authority our of their real-time experience that they have been into while implementing the same within their organization and by observing the same through the secondary source of data. 


\section{SOURCES OF FUNDING}

None.

\section{CONFLICT OF INTEREST}

None.

\section{ACKNOWLEDGMENT}

The authors thank the academic staff who actively participated and provided their responses both in pre and post-gamification studies.

\section{REFERENCES}

[1] Basten, D. (2017), "Gamification", IEEE Software, Vol. 34, No. 5, pp. 76-81.

[2] Bhatnagar, J. (2007), "Talent management strategy of employee engagement in Indian ITES employees: key to retention", Employee relations, Vol. 29, No. 6, pp. 640-663.

[3] Blohm, I., \& Leimeister, J. M. (2013). Gamification. Business \& information systems engineering, 5(4), 275278.

[4] Buhagiar, T., \& Leo, C. (2018). Does Gamification Improve Academic Performance? Journal of Instructional Pedagogies, 20.

[5] Cerasoli, C. P., Nicklin, J. M., Ford, M. T. (2014), "Intrinsic motivation and extrinsic incentives jointly predict performance: A 40-year meta-analysis", Psychological bulletin, Vol. 140, No. 4, pp. 980-1008.

[6] Cronbach, Lee. "J. (1951). Coefficient alpha and the internal structure of tests." Psychometrika 16, no. 3 (1951): 247-334.

[7] Donato, P., \& Link, M. W. (2013). The gamification of marketing research. Marketing News, 47(2), 38-42.

[8] Fitz-Walter, Z., Tjondronegoro, D., \& Wyeth, P. (2011, November). Orientation passport: using gamification to engage university students. In Proceedings of the 23rd Australian computer-human interaction conference (pp. 122-125).

[9] Hammedi, W., Hammedi, W., Leclerq, T., Leclerq, T., Van Riel, A. C., Van Riel, A. C. (2017), "The use of gamification mechanics to increase employee and user engagement in participative healthcare services: A study of two cases", Journal of Service Management, Vol. 28, No. 4, pp. 640-661.

[10] Kapp, K. M. (2013). The gamification of learning and instruction fieldbook: Ideas into practice. John Wiley \& Sons.

[11] Lamm, E., Meeks, M. D. (2009), "Workplace fun: the moderating effects of generational differences", Employee relations, Vol. 31, No. 6, pp. 613-631.

[12] Matzler, K., Renzl, B. (2006), "The relationship between interpersonal trust, employee satisfaction, and employee loyalty", Total quality management and business excellence, $\quad$ Vol. 17, No. 10, pp. 1261-1271.

[13] McCormick, T. (2013). Anthropology of an idea gamification. Foreign Policy, (201), 26.

[14] Meister, J. (2015). Future of work: Using gamification for human resources. LEADERSHIP STRATEGY. Retrived from www.forbes.com.

[15] Millet, J. (2017). The 2018 Human Resources Trends to Keep on Your Radar, Forbs. Retrieved from www.forbes.com.

[16] Mowday, R. T., Steers, R. M., Porter, L. W. (1979), "The measurement of organizational commitment", Journal of vocational behavior, Vol. 14, No. 2, pp. 224-247.

[17] Murugappan, V., Bhattacharyya, D., \& Kim, T. H. (2018). Research Study on Significance of Gamification Learning and i-Campus Using Internet of Things Technology-Enabled Infrastructure. Trends in E-learning, 85.

[18] Narayanan, A. (2014), Gamification for Employee Engagement, Packt Publishing Ltd.

[19] Prasad KDV and Mruthyanjaya Rao (2020). Can gamification intgervention improve engagmenet, performance efficiency of work force - A case study with information technology sector. Journal of Critical Reviews (In press). 
[20] Prasad, K. D. V., Rao, M., \& Vaidya, D. R. (2019). Gamification and Resource Pooling for Improving Operational Efficiency and Effective Management of Human Resources: A Case Study with an Ecommerce Company. International Journal of Management (IJM), 10(6), 76-87.

[21] Robson, K., Plangger, K., Kietzmann, J. H., McCarthy, I., Pitt, L. (2016), "Game on: $\quad$ Engaging customers and employees through gamification", Business horizons, Vol. 59, No. 1, pp. 29-36

[22] Schaufeli, W. B., Bakker, A. B., Salanova, M. (2006), "The measurement of work engagement with a short questionnaire: A cross-national study", Educational and psychological measurement, Vol. 66, No. 4, pp. 701716.

[23] IBM Corp. Released 2019. IBM SPSS Statistics for Windows, Version 26.0. Armonk, NY: IBM Corp.

[24] Werbach, K., Hunter, D. (2012), For the win: How game thinking can revolutionize your business, Wharton Digital Press. 